\title{
Discriminating estuarine nurseries for five fish species through otolith elemental fingerprints
}

\author{
Rita P. Vasconcelos ${ }^{1, *}$, Patrick Reis-Santos ${ }^{1}$, Susanne Tanner $^{1}$, Vanessa Fonseca ${ }^{1}$, \\ Christopher Latkoczy ${ }^{2}$, Detlef Günther ${ }^{2}$, Maria José Costa ${ }^{1,3}$, \\ Henrique Cabral ${ }^{1,3}$
}

\footnotetext{
${ }^{1}$ Instituto de Oceanografia, Faculdade de Ciências da Universidade de Lisboa, Campo Grande, 1749-016 Lisboa, Portugal

${ }^{2}$ ETH Zurich, D-CHAB, Laboratory of Inorganic Chemistry, Wolfgang-Pauli Strasse 10, 8093 Zurich, Switzerland

${ }^{3}$ Faculdade de Ciências da Universidade de Lisboa, Departamento de Biologia Animal. Campo Grande,

1749-016 Lisboa, Portugal
}

\begin{abstract}
Chemical composition of otoliths may provide valuable information in establishing connectivity between nursery grounds and marine coastal stocks. Juveniles of the commercially important fish species Solea solea, S. senegalensis, Platichthys flesus, Diplodus vulgaris and Dicentrarchus labrax were captured in 8 estuarine nursery grounds along the Portuguese coast in July 2005. Concentrations of $\mathrm{Li}, \mathrm{Na}, \mathrm{Mg}, \mathrm{K}, \mathrm{Mn}, \mathrm{Ni}, \mathrm{Cu}, \mathrm{Zn}, \mathrm{Sr}, \mathrm{Cd}, \mathrm{Ba}$ and $\mathrm{Pb}$ were determined in whole juvenile otoliths using solution-based inductively coupled plasma mass spectrometry. Significant differences in the concentration of several elements were found between estuaries and species using ANOVA and MANOVA. Linear discriminant function analysis classified otolith fingerprints between estuaries for all species with good cross-validated results. Depending on the species, 70.2 to $92.0 \%$ of individuals were correctly assigned to their estuary of origin, with discrimination success varying with species, estuaries and number of estuaries in the analysis. Since accurate classification of juvenile fish to their nursery estuary was achieved, fingerprint analysis can be used as a natural habitat tag in assigning adult fish to their estuarine nursery. Ultimately the connectivity between Portuguese estuarine nursery grounds and coastal areas may be estimated, with possible implications for future fisheries and coastal management plans.
\end{abstract}

KEY WORDS: Otolith microchemistry $\cdot$ Fingerprint $\cdot$ Juvenile fish $\cdot$ Estuary $\cdot$ Nursery $\cdot$ Portugal Resale or republication not permitted without written consent of the publisher

\section{INTRODUCTION}

Estuarine systems are recognized worldwide for providing nursery grounds for juveniles of numerous fish species (Beck et al. 2001, Able 2005). For several species, larvae are transported from coastal areas to the estuaries and juveniles remain there during the first year or more, depending on the species, until they recruit to adult marine stocks (Beck et al. 2001, Able 2005).

The definitions and criteria for identification of nursery habitats have evolved. Whereas classically a habitat was considered as a nursery based only on high juvenile densities, a few years ago the concept was redefined (Beck et al. 2001) and applied to habitats that produce relatively more adult recruits per unit area than other juvenile habitats used by a particular species. Recently, Dahlgren et al. (2006) outlined the importance of defining 'effective juvenile habitats' (EJH), which overall contribute most to adult populations. Therefore defining nursery areas requires the identification of areas with high juvenile densities and enhanced survival and growth rates, as well as the application of specific tools to determine their relative contribution to the adult stocks.

Analysis of major and minor element composition of otoliths has been used as a tool for the identification of (1) individuals that have different migratory patterns 
(Kalish 1990, Tsukamoto \& Arai 2001), (2) populations or stocks of fish (Campana 1999, Rooker et al. 2003) and (3) natal origin to near shore and estuarine habitats (Gillanders \& Kingsford 1996, 2000, Thorrold et al. 1998a, 2001, Dorval et al. 2005, Brown 2006a). This is possible due to some particular properties of otoliths reviewed by Campana (1999), Thresher (1999) and Elsdon \& Gillanders (2003). Briefly, otoliths are metabolically inert and trace element uptake reflects the surrounding physical and chemical environment, although incorporation of some elements is affected by physiological regulation. Otoliths are deposited continually and contain daily and annual growth rings that can be used as life-history records reflecting habitat change through time, providing good natural tags of habitat use.

Taking into account otolith properties, coastal fish that spent their juvenile period in estuaries are expected to have an otolith elemental composition which reflects their estuarine life period. The elemental composition of whole juvenile otoliths is commonly used to discriminate juvenile sites of origin as it is representative of the juvenile habitat (Thorrold et al. 1998a, Gillanders \& Kingsford 2000, De Pontual et al. 2000, Dorval et al. 2005, Brown 2006b). Analysis of different regions of otoliths gives information on separate periods of ontogenetic development of the individuals. Point measurements done across daily or annual increments have been used to determine timing of migrations and other life history events (Secor \& Rooker 2000), while analysis of the core (juvenile portion) of adult otoliths has allowed the identification of the habitat of origin of adult fish by comparison with juvenile elemental fingerprints (Gillanders \& Kingsford 1996, Thorrold et al. 2001, Brown 2006a). However, before an elemental fingerprint can be applied as a natural tag, it must be shown to differ amongst geographical locations (Campana et al. 2000).

Along the Portuguese coast several estuaries have been identified as important nursery areas for various commercially important fish species, namely soles Solea solea (Linnaeus, 1758) and S. senegalensis Kaup, 1858, flounder Platichthys flesus (Linnaeus, 1758), sea breams, such as Diplodus vulgaris (Geoffroy SaintHilaire, 1817), and sea bass Dicentrarchus labrax (Linnaeus, 1758) (Cabral \& Costa 1999, Pombo et al. 2002, Veiga et al. 2006, Cabral et al. 2007, Martinho et al. 2007). These species are among some of the most valuable to Portuguese fisheries, and although their average landings represent only $2.2 \%$ of the total weight of marine fish captured in mainland Portugal, they represent over $14 \%$ of total revenue (DGPA-National Directorate of Fisheries and Aquaculture). In view of the commercial importance of these species, and their use of or dependence on estuarine environments, it is fundamental to address the contribution of Portuguese estuarine nurseries to adult populations. To comprehensively evaluate the effective nursery function of these estuaries, it is important to analyse the connectivity of nursery areas as a whole, rather than by single species.

The aim of the present paper is to establish a baseline reference in the use of elemental fingerprints in otoliths to identify estuarine nursery origin for fish species of the Portuguese coast. Specifically, this was done by identifying and discriminating elemental fingerprints in otoliths of juvenile fish of 5 species with different estuarine origins, analysing the variation in elemental composition of fish otoliths among estuaries and observing whether common patterns are found among species. Successful classification and differentiation between estuaries based on otolith chemistry should in the near future allow the identification of estuarine origin of adult fish caught in the marine environment. This could be of major importance in establishing the connectivity between estuarine and marine environments and determining the relative importance and contribution to the marine fish stocks of Portuguese estuarine nurseries.

\section{MATERIALS AND METHODS}

Fish collection. Sampling of age 0 juvenile specimens of Solea solea (common sole), S. senegalensis (Senegal sole), Platichthys flesus (flounder), Diplodus vulgaris (common two banded sea bream) and Dicentrarchus labrax (sea bass) was carried out using a beam trawl during July 2005 in the main estuarine systems of the Portuguese coast (Fig. 1): Douro, Ria de Aveiro, Mondego, Tejo, Sado, Mira, Ria Formosa and Guadiana. Specimens of each species were collected in their main nursery area within the estuaries of their occurrence (Fig. 1). These species are the most representative in terms of estuarine nursery use in each system (Cabral \& Costa 1999, Pombo et al. 2002, Veiga et al. 2006, Cabral et al. 2007, Martinho et al. 2007). To avoid temporal variation in otolith chemistry, sampling was carried out in the shortest time frame possible (a fortnight). Upon collection, fish were stored and transported on ice to the laboratory and preserved frozen until dissection.

Otolith preparation. Ten individuals of each species were selected from each site, and total length and weight of each was measured (Table 1). Sagittal otoliths were extracted using plastic forceps under a binocular lens, and were preserved in decontaminated Eppendorf microcentrifuge tubes. All glassware and plastic containers and implements were first decontaminated by an acid wash in $10 \%$ analytical grade nitric 


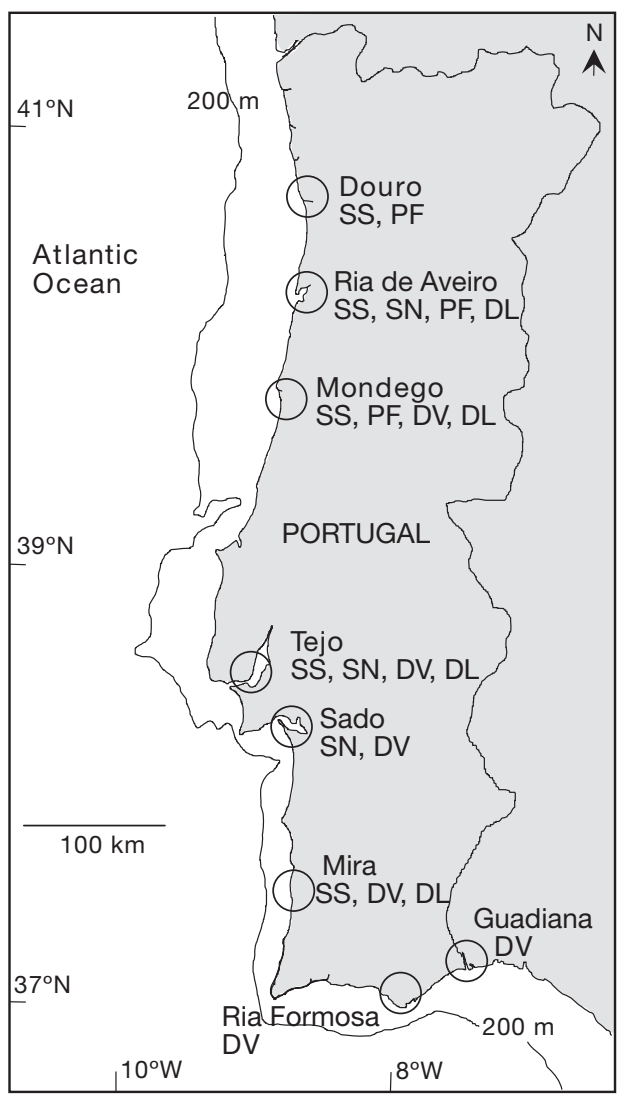

Fig. 1. Location of estuaries on the Portuguese coast and fish species sampled in each system. Species are Solea solea (SS), Solea senegalensis (SN), Platichthys flesus (PF), Diplodus vulgaris (DV) and Dicentrarchus labrax (DL)

acid $\left(\mathrm{HNO}_{3}\right)$ (Merck) for $24 \mathrm{~h}$, rinsed with Normapur water and dried in a laminar flow positive pressure fume hood.

Upon extraction, otoliths were cleaned and decontaminated in a laminar flow positive pressure fume hood, following a protocol adapted from Rooker et al. (2001): (1) immersion in ultrapure water to hydrate biological residues adhering to the surface of the otoliths, (2) immersion in $3 \%$ analytical grade hydrogen peroxide $\left(\mathrm{H}_{2} \mathrm{O}_{2}\right)$ (Pancreac) for $15 \mathrm{~min}$ to dissolve biological residues, (3) immersion in $1 \% \mathrm{HNO}_{3}$ solution for $10 \mathrm{~s}$ to remove superficial contamination, (4) doubleimmersion in ultrapure water for $5 \mathrm{~min}$ to remove acid (5) storage in new previously decontaminated Eppendorf microcentrifuge tubes, left open until dry.

Sample analysis. Chemical composition of whole juvenile otoliths was determined using a solutionbased technique for inductively coupled plasma mass spectrometry (ICP-MS).

The preparation for analysis was done in a class 100 (ISO class 5) clean room. Decontaminated otoliths were weighed on a microbalance $( \pm 0.01 \mathrm{mg})$, dis- solved in $50 \mu \mathrm{HNO}_{3}$ overnight and diluted with ultrapure water to a final acid concentration of $1 \% \mathrm{HNO}_{3}$ (wt/wt).

Otoliths were analysed using a double focusing magnetic sector field instrument ICP-SF-MS (Element2, Thermo Electron Corporation). The instrument is equipped with a compact double-focusing magnetic sector mass spectrometer of reversed Nier-Johnson geometry. All measurements were performed at a medium resolution setting $(\mathrm{m} / \Delta \mathrm{m}=4000)$ to avoid false readings from spectral interferences. In the configuration used, the instrument was equipped with a microflow nebulizer (PFA-100, Elemental Scientific), operated in the self aspirating mode (sample uptake

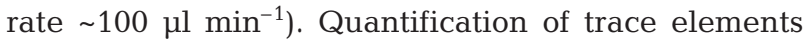
was based on the external calibration method preparing multi-element standards containing the elements of interest in the expected concentration range. To minimize the effect of any plasma fluctuations or different nebulizer aspiration rates between the samples, ${ }^{115}$ In at a known concentration was added to all samples and standards as an internal standard. Concentrations were calculated by linear interpolation (sum of least squares) based on normalization with the internal standard, and on calibration curves made from single element standards (Merck KGaA) covering the individual expected concentration ranges. The calibration was performed at the beginning of each session. The matrix of both the blank and the standard solutions was $1 \% \mathrm{HNO}_{3}$. For the identification of multi-element fingerprints in otoliths from juveniles, the following elements were quantified: ${ }^{7} \mathrm{Li},{ }^{23} \mathrm{Na},{ }^{25} \mathrm{Mg},{ }^{39} \mathrm{~K},{ }^{42} \mathrm{Ca}$, ${ }^{48} \mathrm{Ca},{ }^{55} \mathrm{Mn},{ }^{60} \mathrm{Ni},{ }^{65} \mathrm{Cu},{ }^{66} \mathrm{Zn},{ }^{86} \mathrm{Sr},{ }^{88} \mathrm{Sr},{ }^{111} \mathrm{Cd},{ }^{137} \mathrm{Ba}$ and ${ }^{208} \mathrm{~Pb}$. Two isotopes were read for $\mathrm{Ca}$ and $\mathrm{Sr}$ in order to cross-check the occurrence of any possible interference. Since no interferences were observed, only ${ }^{42} \mathrm{Ca}$ and ${ }^{88} \mathrm{Sr}$ were used for quantification. Otolith samples were read sequentially in random sets of 10, and between sets 2 fish otolith reference materials were analysed for quality control, viz. (1) NIES-022 (National Institute for Environmental Studies, Environ-

Table 1. Solea solea, Solea senegalensis, Platichthys flesus, Diplodus vulgaris, Dicentrarchus labrax. Length (mm) and weight $(\mathrm{g})$ (mean $\pm \mathrm{SE}$ ) of juvenile fish used for extraction of otoliths and determination of elemental fingerprints of estuaries

\begin{tabular}{|lccc|}
\hline Species & $\mathrm{n}$ & Total length & Total weight \\
\hline S. solea & 50 & $91 \pm 3$ & $7.47 \pm 0.65$ \\
S. senegalensis & 30 & $77 \pm 3$ & $4.99 \pm 0.59$ \\
P. flesus & 30 & $72 \pm 1$ & $4.34 \pm 0.38$ \\
D. vulgaris & 60 & $65 \pm 1$ & $4.60 \pm 0.33$ \\
D. labrax & 40 & $82 \pm 3$ & $7.02 \pm 0.8$ \\
\hline
\end{tabular}


ment Agency of Japan, Tsukuba-City, Ibaraki, Japan), and (2) FEBS-01 (National Research Council Canada, Institute for National Measurement Standards, Ottawa, ON, Canada).

Precision for both standard materials ranged between 2 and $5 \%$ RSD (relative standard deviation) and was around $25 \%$ RSD for the lower abundance elements, such as $\mathrm{Ni}, \mathrm{Zn}$, and $\mathrm{Cd}$. The limits of detection were calculated from the individual calibration curves using the 3 sigma criteria $(3 \times$ SD of the blanks divided by the sensitivity) and were (in ppb): Li (0.008), Na (4.344), Mg (10.698), K (18.041), Ca (12.614), Mn (0.014), Ni (0.068), Cu (0.241), Zn (8.378), Sr (0.020), Cd (0.004), Ba (0.017), Pb (0.015). Very few sample readings were below detection and did not specifically affect any element. Mean estimates of precision (\% RSD) were determined for all elements, based on 3 replicate measurements of each otolith sample. Ni and $\mathrm{Cd}$ measurements were of low precision and hence excluded from the analysis. Remaining elements were considered precise, except for 25 samples $(11.9 \%$ of total samples) that were also excluded, since one or more of their elements had a RSD $>10 \%$.

Data analysis. Concentrations of trace elements (originally in $\mathrm{pg} \mathrm{g}^{-1}$ ) were transformed to ratio to $\mathrm{Ca}$ (element:Ca ratio) (Thorrold et al. 1998a, Forrester \& Swearer 2002, Swearer et al. 2003, Dorval et al. 2005, Brown 2006a,b). Raw data for each element were checked for normality and homogeneity of variances, and both assumptions were met after $\log _{10}$ transformation.

Univariate and multivariate statistical techniques were used to explore individual elements and multielement fingerprints. Multivariate analysis of variance (MANOVA) was used to detect differences in elemental compositions of otoliths between juveniles of different species. For each species, differences in otolith chemistry of estuaries were analysed by analysis of variance (ANOVA) for each element, and MANOVA was used to test hypotheses regarding differences in multi-element compositions of otoliths between estuaries

Multi-element compositions of otoliths were analysed using linear discriminant function analysis (LDFA). Linear discriminant functions were built to classify juvenile individuals to one of the estuaries from which each species was collected. Classification accuracies of the discriminant functions for each species were evaluated through the percentage of correctly classified individuals in jacknife (leave-one-out) cross-validations (Gillanders \& Kingsford 1996, 2000, Thorrold et al. 1998a, Swearer et al. 2003, Brazner et al. 2004, Dorval et al. 2005, Brown 2006a). All assumptions were met, including normality and homogeneity of variance-covariance matrices.
The effect of otolith weight on element:Ca ratio was analysed in order to evaluate any possible correlation that might mask the spatial effect and distort the recognition of multi-element fingerprints for the selected estuaries. As ANOVA showed differences in otolith weights between species and also between estuaries for Solea solea $\left(F_{2,42}=3.76, \mathrm{p}<0.01\right)$, S. senegalensis $\left(F_{2,22}=27.02, \mathrm{p}<0.01\right)$, Diplodus vulgaris $\left(F_{5,44}=3.23, \mathrm{p}<0.01\right)$ and Dicentrarchus labrax $\left(F_{3,36}=\right.$ $14.67, \mathrm{p}<0.01)$, linear regression analysis was performed separately for each species to evaluate a possible effect between otolith weight and individual element:Ca ratio. Otolith weight was weakly correlated with $\mathrm{Na}$, in S. solea, and with $\mathrm{Mg}$ and $\mathrm{Sr}$ in D. labrax, amongst others. Two distinct procedures, adapted from Gillanders \& Kingsford (2003) and Brown (2006b), were followed to factor out the effect of otolith weight. The first consisted of subtracting the slope of the regression multiplied by the otolith weight. In the second procedure, an average otolith weight was determined for each species, and the regression was used to estimate the expected element:Ca ratio for each element at this defined (average) weight. Subsequently, the specific residual from the regression was added to the estimated element:Ca ratio. Both these procedures had little effect on the results, and did not change the significance of the initial data nor the corresponding discriminant analysis, therefore the original data were utilized.

\section{RESULTS}

Through the observation of element:Ca ratio (Fig. 2) some patterns were visible that may be relevant for the separation and classification of the estuaries. Ria de Aveiro data showed peaks of several elements in different species, namely $\mathrm{Zn}, \mathrm{Cu}$ and Li for Solea solea, $\mathrm{Ba}, \mathrm{Cu}$ and $\mathrm{Li}$ for Platichthys flesus and $\mathrm{Mg}$ for both Solea spp. With the exception of $\mathrm{Sr}$ and $\mathrm{K}$, element:Ca ratios in Diplodus vulgaris from Ria Formosa were generally low. $\mathrm{Ba}, \mathrm{Pb}, \mathrm{Cu}$, and $\mathrm{Li}$ :Ca ratios were inverted for $S$. senegalensis and D. vulgaris between the Tejo and Sado estuaries. Higher values of these elements were found in the Tejo for $S$. senegalensis and in the Sado for D. vulgaris. In general, both sole species and flounder showed higher levels of Mn and $\mathrm{Zn}$ compared to the sea bream and sea bass.

Significant differences in the elemental composition of otoliths were found between juveniles of all species (MANOVA $F_{5,20}=24.8, \mathrm{p}<0.001$ ).

ANOVA revealed significant differences between estuaries in otolith chemistry of each of the 5 species (Table 2). Mn and Ba were significantly different between estuaries for all 5 species, while for $\mathrm{Li}$, differ- 
ences occurred in 4 species. In addition, the following elements were significantly different between estuaries: for Solea solea: $\mathrm{Na}, \mathrm{Mg}, \mathrm{K}, \mathrm{Zn}$; for Platichthys flesus: $\mathrm{Na}, \mathrm{Mg}, \mathrm{Cu}$ and $\mathrm{Pb}$; and for Dicentrachus labrax: $\mathrm{Na}$, $\mathrm{Mg}, \mathrm{K}, \mathrm{Sr}$, and $\mathrm{Pb}$. In Diplodus vulgaris, all elements were significantly different between estuaries, and for S. senegalensis, only K and Zn were not significant.
In each species, significant differences were found in the multi-element fingerprints of juveniles collected in different estuaries (Table 3).

Through LDFA, a clear discrimination between the estuaries was achieved for each species based on otolith chemical composition, with very good crossvalidation results for most of the estuaries. Considering
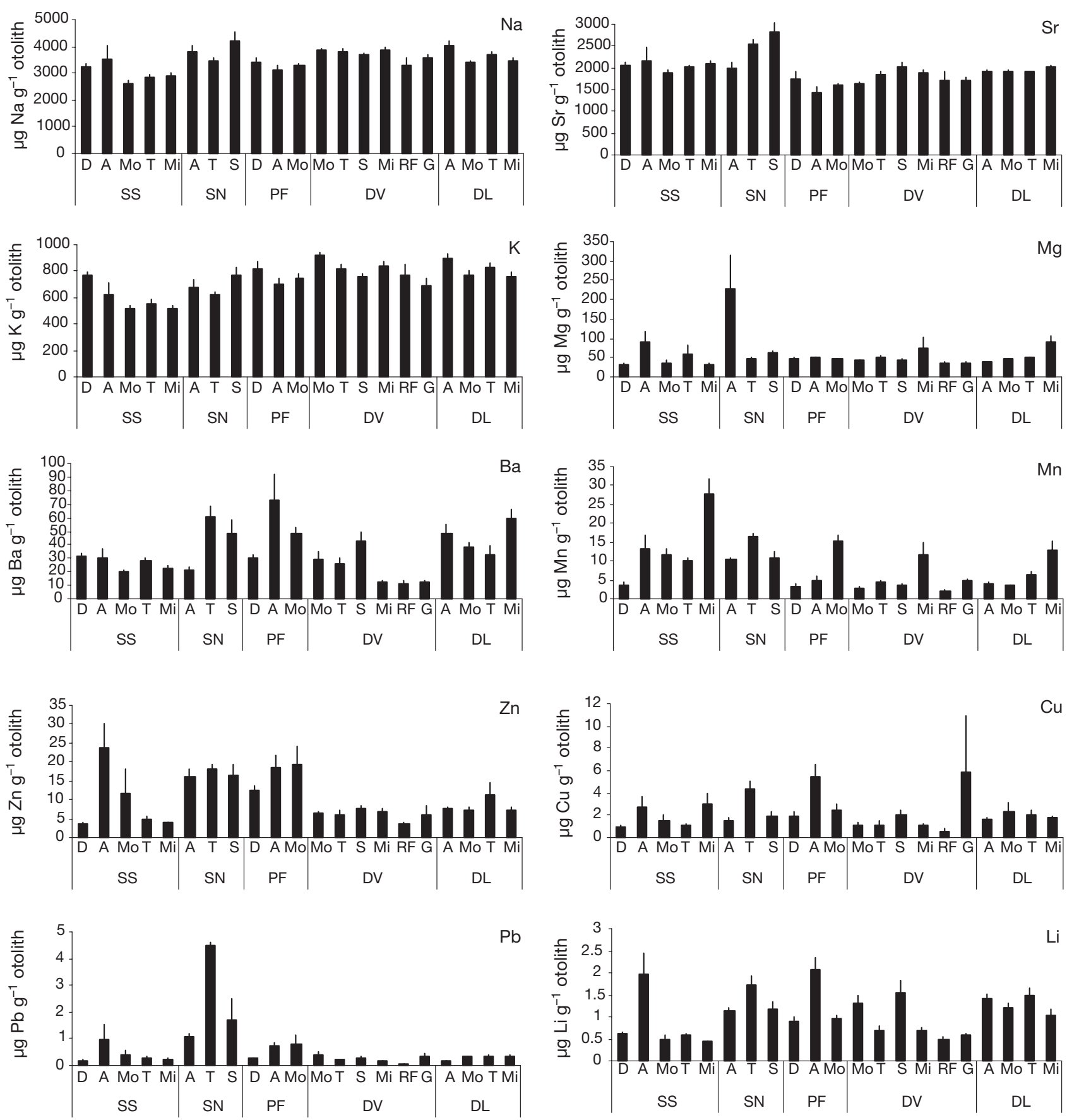

Fig. 2. Solea solea (SS), Solea senegalensis (SN), Platichthys flesus (PF), Diplodus vulgaris (DV) and Dicentrarchus labrax (DL). Concentrations (mean $+\mathrm{SE}, \mathrm{n}=185)$ of $\mathrm{Li}, \mathrm{Na}, \mathrm{Mg}, \mathrm{K}, \mathrm{Mn}, \mathrm{Cu}, \mathrm{Zn}, \mathrm{Sr}, \mathrm{Ba}, \mathrm{Pb}\left(\mathrm{\mu g} \mathrm{g}^{-1}\right)$ in otoliths of juveniles collected in $8 \mathrm{Portu}-$ guese estuaries: Douro (D), Ria de Aveiro (A), Mondego (Mo), Tejo (T), Sado (S), Mira (Mi), Ria Formosa (RF) and Guadiana (G) 
Table 2. Solea solea, Solea senegalensis, Platichthys flesus, Diplodus vulgaris, Dicentrarchus labrax. Results of ANOVA comparisons of mean element:Ca ratios ( $\mathrm{Li}, \mathrm{Na}, \mathrm{Mg}, \mathrm{K}, \mathrm{Mn}, \mathrm{Cu}, \mathrm{Zn}, \mathrm{Sr}, \mathrm{Ba}, \mathrm{Pb}$ ) in otoliths of juveniles collected in 8 estuarine systems on the Portuguese coast. ${ }^{*} \mathrm{p}<0.05,{ }^{* *} \mathrm{p}<0.01,{ }^{* * *} \mathrm{p}<0.001$

\begin{tabular}{|c|c|c|c|c|c|c|c|c|c|c|}
\hline \multirow[t]{2}{*}{$\begin{array}{l}\text { Source } \\
\text { df }\end{array}$} & \multicolumn{2}{|c|}{$\begin{array}{l}\text { Solea solea } \\
\text { Estuary } \\
4,42\end{array}$} & \multicolumn{2}{|c|}{$\begin{array}{c}\text { Solea senegalensis } \\
\text { Estuary } \\
2,22\end{array}$} & \multicolumn{2}{|c|}{$\begin{array}{c}\text { Platichthys flesus } \\
\text { Estuary } \\
2,25\end{array}$} & \multicolumn{2}{|c|}{$\begin{array}{c}\text { Diplodus vulgaris } \\
\text { Estuary } \\
5,44\end{array}$} & \multicolumn{2}{|c|}{$\begin{array}{c}\text { Dicentrarchus labrax } \\
\text { Estuary } \\
3,31\end{array}$} \\
\hline & $F$ & $\mathrm{p}$ & $F$ & $\mathrm{p}$ & $F$ & $\mathrm{p}$ & $F$ & $\mathrm{p}$ & F & $\mathrm{p}$ \\
\hline $\mathrm{Li}$ & 19.059 & $<0.001^{* * *}$ & 9.468 & $0.001^{* *}$ & 19.004 & $<0.001^{* * *}$ & 11.276 & $<0.001^{* * *}$ & 0.450 & 0.719 \\
\hline $\mathrm{Na}$ & 6.298 & $<0.001^{* * *}$ & 10.100 & $<0.001^{* * *}$ & 17.528 & $<0.001^{* * *}$ & 4.150 & $0.004^{* *}$ & 3.010 & $0.045^{*}$ \\
\hline $\mathrm{Mg}$ & 3.444 & $0.016^{* *}$ & 26.682 & $<0.001^{* * *}$ & 4.162 & $0.028^{*}$ & 3.282 & $0.013^{*}$ & 10.648 & $<0.001^{* * *}$ \\
\hline $\mathrm{K}$ & 18.426 & $<0.001^{* * *}$ & 0.925 & 0.412 & 2.499 & 0.103 & 5.601 & $<0.001^{* * *}$ & 3.062 & $0.043^{*}$ \\
\hline $\mathrm{Mn}$ & 24.401 & $<0.001^{* * *}$ & 25.963 & $<0.001^{* * *}$ & 23.664 & $<0.001^{* * *}$ & 8.504 & $<0.001^{* * *}$ & 19.642 & $<0.001^{* * *}$ \\
\hline $\mathrm{Cu}$ & 0.841 & 0.507 & 10.486 & $<0.001^{* * *}$ & 8.236 & $0.002^{* *}$ & 3.624 & $0.008^{* *}$ & 0.882 & 0.461 \\
\hline $\mathrm{Zn}$ & 14.990 & $<0.001^{* * *}$ & 3.066 & 0.669 & 1.272 & 0.298 & 5.229 & $<0.001^{* * *}$ & 0.322 & 0.809 \\
\hline $\mathrm{Sr}$ & 0.745 & 0.567 & 25.116 & $<0.001^{* * *}$ & 1.203 & 0.317 & 15.528 & $<0.001^{* * *}$ & 13.147 & $<0.001^{* * *}$ \\
\hline $\mathrm{Ba}$ & 3.364 & $0.018^{*}$ & 10.731 & $<0.001^{* * *}$ & 4.775 & $0.018^{*}$ & 9.116 & $<0.001^{* * *}$ & 6.779 & $0.001^{* *}$ \\
\hline $\mathrm{Pb}$ & 1.285 & 0.291 & 17.384 & $<0.001^{* * *}$ & 6.619 & $0.005^{* *}$ & 16.286 & $<0.001^{* * *}$ & 3.963 & $0.017^{*}$ \\
\hline
\end{tabular}

Table 3. Solea solea, Solea senegalensis, Platichthys flesus, Diplodus vulgaris, Dicentrarchus labrax. Results of MANOVA comparisons of mean element:Ca ratios ( $\mathrm{Li}, \mathrm{Na}, \mathrm{Mg}, \mathrm{K}, \mathrm{Mn}$, $\mathrm{Cu}, \mathrm{Zn}, \mathrm{Sr}, \mathrm{Ba}, \mathrm{Pb}$ ) in otoliths of juveniles collected in 8 estuarine systems of the Portuguese coast

\begin{tabular}{|lccc|}
\hline Source & df & $F$ & $p$ \\
\hline Solea solea, Estuary & 40 & 6.44 & $<0.001$ \\
Solea senegalensis, Estuary & 20 & 13.24 & $<0.001$ \\
Platichthys flesus, Estuary & 20 & 9.05 & $<0.001$ \\
Diplodus vulgaris, Estuary & 50 & 7.7 & $<0.001$ \\
Dicentrarchus labrax, Estuary & 30 & 7.5 & $<0.001$ \\
\hline
\end{tabular}

all cross-validation results, $82 \%$ of all individuals from the 5 species studied were correctly assigned to their estuary of origin (Table 4 ).

For Solea solea, $70.2 \%$ of all individuals were correctly classified to their estuary of origin. Highest classification accuracy was reached in the Douro estuary (100\%), with high rates for Tejo and Mira (70 and 90\%) and poor results for discerning individuals from the Mondego estuary (12.5\%). The first 2 canonical discriminant functions defined in the LDFA accounted for $92.2 \%$ of total variance, and discrimination was based on differences in Mn, K, Li and Zn.

Solea senegalensis individuals were correctly crossvalidated in $92 \%$ of the cases for the 3 estuaries. The best classification results occurred for Ria de Aveiro and Tejo estuaries (100\%), and there were high classification results for the Sado estuary (75\%). LDFA defined 2 canonical discriminant functions that explained all variance. Discrimination was mainly based on differences in $\mathrm{Mg}, \mathrm{Mn}, \mathrm{Sr}, \mathrm{Na}$ and $\mathrm{Cu}$.

Cross-validation results for Platichthys flesus revealed $89.3 \%$ of correctly classified individuals, with high classification rates for the Douro, Ria de Aveiro and Mondego estuaries (between 100 and $80 \%$ ). Total variance was explained by the 2 defined canonical discriminant functions, and discrimination was based mainly on differences in $\mathrm{Mn}, \mathrm{Na}$ and $\mathrm{Li}$ between estuaries.

Diplodus vulgaris had high cross-validation results $(84.0 \%)$, due to good classification rates among most of the estuaries from the Mondego $(100 \%)$ to the Tejo, Mira and Guadiana estuaries $(77.8 \%)$. The first 2 canonical discriminant functions of the LDFA explained $76.4 \%$ of total variance. Discrimination of estuaries in the first 2 functions was based on differences in $\mathrm{Pb}, \mathrm{K}, \mathrm{Mn}, \mathrm{Ba}$ and $\mathrm{Li}$.

For Dicentrarchus labrax, cross-validation rate was $77.1 \%$. High classification occurred for Ria de Aveiro, Mondego and Mira estuaries (75 to $90 \%$ ), but was only moderate for the Tejo $(66.7 \%)$. The first 2 canonical discriminant functions of the LDFA explained $93.5 \%$ of total variance. Discrimination was mainly based on differences in $\mathrm{Mg}, \mathrm{Mn}, \mathrm{Sr}, \mathrm{Pb}$ and $\mathrm{Ba}$ amongst the estuaries.

Pooling all species, the percentage of correct classification also varied between estuaries. The Douro $(100 \%)$ was the best discriminated estuary. The Mondego was the worst $(72.7 \%)$, due to the results with Solea solea, and the remaining estuaries had correct classification results between 77.8 (Guadiana) and 85.7\% (Ria Formosa).

\section{DISCUSSION}

Chemical composition of otoliths from juveniles of 5 species collected in 8 estuaries of the Portuguese coast allowed accurate discrimination of their origins, and may prove useful as a natural tag of estuarine nursery 
origin. Ratios to Ca results of major and minor elements (Li, Na, Mg, K, Ca, Mn, Cu, Zn, Sr, Ba and Pb) analysed through univariate and multivariate techniques and through discriminant analysis correctly classified $82 \%$ of all individuals to their estuary of origin.

Elements identified by ANOVA as significantly different between estuaries for each species, namely with $\mathrm{p}<0.001$, had higher canonical correlation coefficients in the first 2 discriminant functions of the LDFA. The key elements for the discrimination of these estuaries differed with species, which also suggests that otolith fingerprints should be determined for each species, particularly if this is to be used as the basis for identifying estuarine origin of adults. Other studies also found differences in otolith fingerprints between several species (Dove et al. 1996, Gillanders \& Kingsford 2003, Swearer et al. 2003).

Several authors have built discrimination models based on a reduced number of elements, although they initially analysed a large set (De Pontual et al. 2000,
Forrester \& Swearer 2002, Brazner et al. 2004). Attempts were made to define a reduced core of statistically significant elements that would best fit all species and estuaries, but this did not improve the differentiation between estuaries. The best outcome for all species and estuaries in this study was obtained using all elements analysed. The discrimination in each species may require only a set of relevant elements, but the complete group is more reliable in defining the fingerprint of each estuary. A larger set of diagnostic elements in the analysis increased the complexity of the signal read in each estuary and allowed an accurate discrimination of the estuaries for the 5 species. Considering this, and from a cost-benefit perspective, discrimination of natal estuaries individually for these 5 species could be achieved using a reduced set of elements. However, if the objective is to ascertain otolith fingerprints for several species in a number of estuaries, then the use of a wide array of elements is recommended.

Table 4. Solea solea, Solea senegalensis, Platichthys flesus, Diplodus vulgaris, Dicentrarchus labrax. Cross-validated classification results (\%) of discriminant function analysis of juveniles. Specimens were collected from Douro (D), Ria de Aveiro (A), Mondego (Mo), Tejo (T), Sado (S), Mira (Mi), Ria Formosa (RF) and Guadiana (G), and classification to an estuary was based on multielement fingerprints ( $\mathrm{Li}, \mathrm{Na}, \mathrm{Mg}, \mathrm{K}, \mathrm{Mn}, \mathrm{Cu}, \mathrm{Zn}, \mathrm{Sr}, \mathrm{Ba}$ and $\mathrm{Pb}$ ). Values in bold indicate percentage of fish correctly classified to their estuary of origin. $\mathrm{n}=$ number of individuals

\begin{tabular}{|c|c|c|c|c|c|c|c|c|c|c|}
\hline \multirow{2}{*}{ Species } & \multirow{2}{*}{ Estuary } & & & & \multicolumn{2}{|c|}{ Predicted estuary } & \multirow[b]{2}{*}{ Mi } & \multirow[b]{2}{*}{$\mathrm{RF}$} & \multirow[b]{2}{*}{ G } & \multirow{2}{*}{$\mathrm{n}$} \\
\hline & & $\mathrm{D}$ & A & Mo & $\mathrm{T}$ & $\mathrm{S}$ & & & & \\
\hline \multirow[t]{5}{*}{ S. solea ${ }^{\mathrm{a}}$} & $\mathrm{D}$ & 100 & 0 & 0 & 0 & & 0 & & & 10 \\
\hline & A & 0 & 66.7 & 22.2 & 0 & & 11.1 & & & 9 \\
\hline & Mo & 0 & 25 & 12.5 & 37.5 & & 25 & & & 8 \\
\hline & $\mathrm{T}$ & 0 & 0 & 20 & 70 & & 10 & & & 10 \\
\hline & $\mathrm{Mi}$ & 0 & 0 & 0 & 10 & & 90 & & & 10 \\
\hline \multicolumn{11}{|c|}{ a $70.2 \%$ of all individuals correctly classified to their estuary of origin } \\
\hline \multirow[t]{3}{*}{ S. senegalensis ${ }^{\mathrm{b}}$} & A & 100 & & & 0 & 0 & & & & 7 \\
\hline & $\mathrm{T}$ & 0 & & & 100 & 0 & & & & 10 \\
\hline & $\mathrm{S}$ & 0 & & & 25 & 75 & & & & 8 \\
\hline \multicolumn{11}{|c|}{${ }^{\mathrm{b}} 92.0 \%$ of all individuals correctly classified to their estuary of origin } \\
\hline \multirow[t]{3}{*}{ P. flesus ${ }^{c}$} & $\mathrm{D}$ & 100 & 0 & 0 & & & & & & 10 \\
\hline & A & 12.5 & 87.5 & 0 & & & & & & 8 \\
\hline & Mo & 0 & 20 & 80 & & & & & & 10 \\
\hline \multicolumn{11}{|c|}{${ }^{\mathrm{c}} 89.3 \%$ of all individuals correctly classified to their estuary of origin } \\
\hline \multirow[t]{6}{*}{ D. vulgaris ${ }^{\mathrm{d}}$} & Mo & & & 100 & 0 & 0 & 0 & 0 & 0 & 9 \\
\hline & $\mathrm{T}$ & & & 0 & 77.8 & 0 & 22.2 & 0 & 0 & 9 \\
\hline & $\mathrm{S}$ & & & 0 & 14.3 & 85.7 & 0 & 0 & 0 & 7 \\
\hline & $\mathrm{Mi}$ & & & 0 & 22.2 & 0 & 77.8 & 0 & 0 & 9 \\
\hline & $\mathrm{RF}$ & & & 0 & 14.3 & 0 & 0 & 85.7 & 0 & 7 \\
\hline & $\mathrm{G}$ & & & 0 & 22.2 & 0 & 0 & 0 & 77.8 & 9 \\
\hline \multicolumn{11}{|c|}{${ }^{\mathrm{d}} 84.0 \%$ of all individuals correctly classified to their estuary of origin } \\
\hline \multirow[t]{4}{*}{ D. labrax ${ }^{\mathrm{e}}$} & A & & 75 & 0 & 25 & & 0 & & & 8 \\
\hline & Mo & & 0 & 75 & 25 & & 0 & & & 8 \\
\hline & $\mathrm{T}$ & & 0 & 33.3 & 66.7 & & 0 & & & 9 \\
\hline & $\mathrm{Mi}$ & & 0 & 10 & 0 & & 90 & & & 10 \\
\hline
\end{tabular}


In terms of classification accuracies, similar results have been found for juvenile Pelates sexlineatus from 7 Australian estuaries, with 50 to $100 \%$ of individuals correctly classified in a 2 yr study, averaging around $75 \%$ each year (Gillanders \& Kingsford 2000). Variations in otolith fingerprints of 3 Sparidae species also distinguished a number of Australian estuaries (Gillanders \& Kingsford 2003) and high classification rates (above $80 \%$ ) were also found for Cynoscion nebulosus in Chesapeake Bay, USA (Dorval et al. 2005) and for Cynoscion regalis in estuaries along the eastern coast of the USA (Thorrold et al. 1998a). Our results were equivalent to those obtained in these studies, with several $100 \%$ correct classifications, and a minimum cross validated classification for a species of $70.2 \%$. However, it is noteworthy that to achieve the present results, it was not necessary to proceed to site pooling (Gillanders \& Kingsford 2003), or combinations of different techniques (e.g. isotopic analysis of the otoliths, in addition to trace element analysis; Thorrold et al. 1998a).

In the Bay of Biscay, up to $91 \%$ of Solea solea juveniles were correctly assigned to their origin (De Pontual et al. 2000), but few other studies have used these techniques for European estuaries (Daverat et al. 2004), or coastal areas (Gillanders et al. 2001, Geffen et al. 2003). It is of fundamental importance to address this issue for improvement of stock assessments and for common stock management, because these estuarine environments are significant nursery areas for several highly commercial species intensively fished within the European Union. In recent years, research has been focused mainly on stock discrimination or natal origin of marine species in the North Eastern Atlantic, Mediterranean and North seas (Rooker et al. 2003, Swan et al. 2006).

Our success in distinguishing individuals and assigning them correctly to estuaries depended on species, estuary and number of estuaries in the analysis. The Douro estuary was the best discriminated estuary, and among species Solea senegalensis was most often correctly classified. S. senegalensis and Platichthys flesus collected in a smaller number of estuaries produced higher cross-validation results than species sampled in larger sets of estuaries. Analysing 3 Sparidae species, Gillanders \& Kingsford (2003) also found that overlap in elemental fingerprints was higher with an increase in the number of sampled estuaries, and stated that lower classification rates may restrict discrimination to groups of estuaries, rather than to individual estuaries. Solutions for this challenge may involve the analysis of a broader set of elements and stable isotopes, in order to define a unique fingerprint of each estuary. Classification accuracies can be improved in poorly classified habitats by combining the use of trace elements and stable isotopes $\left(\delta^{13} \mathrm{C}\right.$ and $\delta^{18} \mathrm{O}$ ) (Thorrold et al. 1998a,
2001). The importance of isotopic ratios in connectivity studies has been reviewed by Herzka (2005), and recently the advantages of 'rare earth elements' (REE) have also been explored (Dorval et al. 2005). Although high cross-validated classifications were achieved for the Portuguese estuaries analysed, application of these additional techniques might prove valuable in achieving better discriminations for $S$. solea from the Mondego estuary, and Dicentrarchus labrax (for all estuaries) to levels approaching those obtained for the remaining species.

There were strong differences in elemental composition of otoliths of juvenile fish from different estuaries and species sampled. These spatial differences are the result of several factors that influence the chemical composition of otoliths in a complex manner governed by numerous biological and geological sources (Campana 1999). Although still not fully understood, several factors, including temperature and salinity, are known to influence the incorporation of some elements into otoliths. Water chemistry is assumed to be the primary source of elements incorporated into otoliths, whilst diet has a minimal effect in uptake (see reviews by Campana 1999, Thresher 1999, Elsdon \& Gillanders 2003). The geological composition of the watersheds and differences in sediment type, water flow, salinity range and location of the nursery grounds within the estuary (summarized for these estuaries by Cabral et al. 2007) are suggested as factors responsible for spatial variations in the multi-element fingerprints. Differences between the 5 species in the sampled estuaries, particularly between Pleuronectiforme and Perciforme species, may be attributable to different incorporation of elements by physiological and ontogenetic regulation, habitat use (bentho-pelagic or benthic), estuarine residence time after larval entry and diet. Even though much remains to be investigated, especially concerning incorporation mechanisms, this does not compromise the validity of the analysis of elemental fingerprints as habitat use tags (Thorrold et al. 1998b).

Differential anthropogenic pressures exist between the estuaries sampled, namely in water and sediment contamination (Vasconcelos et al. 2007). Concentrations of elements such as $\mathrm{Cu}, \mathrm{Zn}, \mathrm{Mn}, \mathrm{Cd}$ and $\mathrm{Pb}$ in estuarine systems are greatly enriched by human activity and are often used in otolith fingerprint studies with good discrimination results (Gillanders \& Kingsford 1996, 2003 Forrester \& Swearer 2002, Geffen et al. 2003). Our analysis of these elements proved useful and corroborated expectations, since they showed high correlations in the discrimination functions. Existing knowledge of sources and contamination levels that influence water chemistry are valuable in selecting elements which may be worthwhile analysing for discrimination purposes. 
Since older individuals may migrate out of the nursery area (Coggan \& Dando 1988, Cabral \& Costa 1999), variations in otolith composition due to shifts in habitat use with age are minimized by analysing young age 0 juveniles. All fish were captured in the same time period and are expected to have similar estuarine residence times. The observed differences in total length and otolith weights between fish of several estuaries are considered a result of the differing estuarine conditions (temperature, salinity, food availability, inter and intra specific competition, amongst others) that influence fish growth. The differences in otolith weights for Senegalese sole, sea bream and sea bass, did not affect the patterns for discrimination of the spatial variation of otolith chemistry. Gillanders \& Kingsford (2003) also obtained analogous classification results using the original and detrended data for otolith weight effect.

Spatial discrimination and classification were highly successful for all 5 species, with misclassification problems occurring only for Solea solea specimens from the Mondego estuary, which were mostly classified as originating from the Tejo. As for S. solea, misclassified sea bass from the Mondego were classified as belonging to the Tejo. The lack of differences in otolith chemistry may imply that the environments are relatively homogeneous (Thresher 1999, Gillanders et al. 2001) between the nursery areas, hence the overlap in discrimination. Moreover, Platichthys flesus collected from the same site as $S$. solea were correctly identified, but not discriminated against the Tejo. Difficulties in identifying the Mondego estuary may diminish with the use of new elements, including REE and stable isotopes. Misclassifications of individuals are not easily interpreted, but they are still important steps towards understanding the limits and possibilities of these techniques.

Successful discrimination of estuarine nurseries was accomplished through otolith elemental fingerprints, fulfilling one of the requirements for their possible use as natural tags (Campana et al. 2000). Estuarine origin of juvenile fish was accurately identified based on otolith fingerprints, which were established separately for each species since a chemical signature common to all species representing one estuary was not achieved. Several methodologies based on laser ablation (Thorrold et al. 2001, Gillanders 2002) or solution-based ICP-MS (Gillanders \& Kingsford 1996, Gillanders 2005, Brown 2006a) could be used to determine elemental fingerprints found in the otolith cores of adult fish caught off the Portuguese coast for comparison with the juvenile estuarine fingerprints we have established. The comparison should be made by application of the discriminant canonical functions obtained from juveniles to the adult data (Gillanders \& Kingsford 1996, Thorrold et al. 2001, Brown 2006a). Future research on elemental fingerprints and on the identification of adults originating from each estuarine nursery will ultimately allow the quantification of the relative contribution of each of these areas. For management, a multi-species approach should provide more relevant information on the nursery value and ecological importance of these estuaries, since the complementary use of a selected group of species may result in information different from an approach based on single species.

To be truly effective, connectivity assessments should characterize all possible contributing estuaries and the element concentrations in the otolith core must remain stable between juveniles and adults (Campana 1999). In order to avoid misclassification of individuals originating from uncharacterized estuaries, research on juvenile fingerprints was directed to the main Portuguese estuaries, which potentially contribute most to coastal stocks. Present results are a step towards establishing juvenile movement to adult habitats, which must be examined in nursery studies (Beck et al. 2001). Additionally, focus should be given in future studies to possible intra-estuarine and temporal variations, which have been reported to occur in some estuarine systems (Gillanders \& Kingsford 2000, Elsdon \& Gillanders 2003, Dorval et al. 2005). If temporal variability in elemental fingerprints is detected, a library of nursery fingerprints could be established and matched against fingerprints from otoliths of adults of the corresponding age class (Thorrold et al. 2001, Brazner et al. 2004, Brown 2006b).

Identifying natal origin, and understanding and estimating connectivity between estuarine nurseries and adult populations, has the potential to aid fisheries and integrated coastal management, prioritizing management and conservation efforts towards nurseries and effective juvenile habitats.

Acknowledgements. We thank all involved in fish sampling. We also thank the anonymous referees for their valuable comments. This study was co-funded by the European Union through the FEDER-Portuguese Fisheries Programme (MARE), as well as by the 'Fundação para a Ciência e a Tecnologia' (FCT). R.P.V. was funded with a PhD grant from FCT.

\section{LITERATURE CITED}

Able KW (2005) A re-examination of fish estuarine dependence: evidence for connectivity between estuarine and ocean habitats. Estuar Coast Shelf Sci 64:5-17

Beck MW, Heck KL, Able KW, Childers DL and 9 others (2001) The identification, conservation, and management of estuarine and marine nurseries for fish and invertebrates. BioScience 51:633-641

Brazner JC, Campana SE, Tanner DK (2004) Habitat fingerprints for Lake Superior coastal wetlands derived from elemental analysis of yellow perch otoliths. Trans Am Fish Soc 133:692-704 
Brown JA (2006a) Using the chemical composition of otoliths to evaluate the nursery role of estuaries for English sole Pleuronectes vetulus populations. Mar Ecol Prog Ser 306: 269-281

Brown JA (2006b) Classification of juvenile flatfishes to estuarine and coastal habitats based on the elemental composition of otoliths. Estuar Coast Shelf Sci 66:594-611

Cabral HN, Costa MJ (1999) Differential use of nursery areas within the Tagus estuary by sympatric soles, Solea solea and Solea senegalensis. Environ Biol Fish 56:389-397

Cabral HN, Vasconcelos R, Vinagre C, França S and 9 others (2007) Relative importance of estuarine flatfish nurseries along the Portuguese coast. J Sea Res 57:209-217

Campana SE (1999) Chemistry and composition of fish otoliths: pathways, mechanisms and applications. Mar Ecol Prog Ser 188:263-297

Campana SE, Chouinard GA, Hanson JM, Fréchet A, Brattey $\mathrm{J}$ (2000) Otolith elemental fingerprints as biological tracers of fish stocks. Fish Res 46:343-357.

Coggan RA, Dando PR (1988) Movements of juvenile Dover sole, Solea solea (L.), in the Tamar Estuary, South-western England. J Fish Biol 33 (Suppl A):177-184

Dahlgren CP, Kellison GT, Adams AJ, Gillanders BM and 5 others (2006) Marine nurseries and effective juvenile habitats: concepts and applications. Mar Ecol Prog Ser 312: 291-295

Daverat F, Elie P, Lahaye M (2004) Microchemistry contribution to a first approach to the diversity of life histories of eels from the lower part of the Gironde-Garonne-Dordogne watershed. Cybium 28:83-90

De Pontual H, Lagardere F, Troadec H, Batel A, Desaunay Y, Koutsikopoulos C (2000) Otoliths imprinting of sole (Solea solea) from the Bay of Biscay: a tool to discriminate individuals from nursery origins? Oceanol Acta 23: $497-513$

Dorval E, Jones CM, Hannigan R, van Montfrans J (2005) Can otolith chemistry be used for identifying essential seagrass habitats for juvenile spotted seatrout, Cynoscion nebulosus, in Chesapeake Bay? Mar Freshw Res 56: 645-653

Dove SG, Gillanders BM, Kingsford MJ (1996) An investigation of chronological differences in the deposition of trace metals in the otoliths of two temperate reef fishes. J Exp Mar Biol Ecol 205:15-33

Elsdon TS, Gillanders BM (2003) Reconstructing migratory patterns of fish based on environmental influences on otolith chemistry. Rev Fish Biol Fish 13:219-235

Forrester GE, Swearer SE (2002) Trace elements in otoliths indicate the use of open-coast versus bay nursery habitats by juvenile California halibut. Mar Ecol Prog Ser 241: 201-213

Geffen AJ, Jarvis K, Thorpe JP, Leah RT, Nash RDM (2003) Spatial differences in the trace element concentrations of Irish Sea plaice Pleuronectes platessa and whiting Merlangius merlangus otoliths. J Sea Res 50:245-254

Gillanders BM (2002) Connectivity between juvenile and adult fish populations: do adults remain near their recruitment estuaries? Mar Ecol Prog Ser 240:215-223

Gillanders BM (2005) Using elemental chemistry of fish otoliths to determine connectivity between estuarine and coastal habitats. Estuar Coast Shelf Sci 64:47-57

Gillanders BM, Kingsford MJ (1996) Elements in otoliths may elucidate the contribution of estuarine recruitment to sustaining coastal reef populations of a temperate reef fish. Mar Ecol Prog Ser 141:13-20

Gillanders BM, Kingsford MJ (2000) Elemental fingerprints of otoliths of fish may distinguish estuarine 'nursery' habitats. Mar Ecol Prog Ser 201:273-286

Gillanders BM, Kingsford MJ (2003) Spatial variation in elemental composition of otoliths of three species of fish (family Sparidae). Estuar Coast Shelf Sci 57:1049-106

Gillanders BM, Sanchez-Jerez P, Bayle-Sempere J, RamosEspla A (2001) Trace elements in otoliths of the twobanded bream from a coastal region in the south-west Mediterranean: are there differences among locations? J Fish Biol 59:350-363

Herzka SZ (2005) Assessing connectivity of estuarine fishes based on stable isotope ratio analysis. Estuar Coast Shelf Sci 64:58-69

Kalish JM (1990) Use of otolith microchemistry to distinguish the progeny of sympatric anadromous and non-anadromous salmonids. Fish Bull 88:657-666

Martinho F, Leitão R, Neto JM, Cabral HN, Marques JC, Pardal MA (2007) The use of nursery areas by juvenile fish in a temperate estuary, Portugal. Hydrobiologia 587:281-290

Pombo L, Elliott M, Rebelo JE (2002) Changes in the fish fauna of the Ria de Aveiro estuarine lagoon (Portugal) during the twentieth century. J Fish Biol 61:167-181

Rooker JR, Secor DH, Zdanowicz VS, De Metrio G, Relini LO (2003) Identification of Atlantic bluefin tuna (Thunnus thynnus) stocks from putative nurseries using otolith chemistry. Fish Oceanogr 12:75-84

Rooker JR, Zdanowicz VS, Secor DH (2001) Chemistry of tuna otoliths: assessment of base composition and postmortem handling effects. Mar Biol 139:35-43

Secor DH, Rooker JR (2000) Is otolith strontium a useful scalar of life cycles in estuarine fishes? Fish Res 46:359-371

Swan SC, Geffen AJ, Morales-Nin B, Gordon JDM, Shimmield T, Sawyer T, Massuti E (2006) Otolith chemistry: an aid to stock separation of Helicolenus dactylopterus (bluemouth) and Merluccius merluccius (European hake) in the Northeast Atlantic and Mediterranean. ICES J Mar Sci 63: $504-513$

Swearer SE, Forrester GE, Steele MA, Brooks AJ, Lea DW (2003) Spatio-temporal and interspecific variation in otolith trace-elemental fingerprints in a temperate estuarine fish assemblage. Estuar Coast Shelf Sci 56:1111-1123

Thorrold SR, Jones CM, Swart PK, Targett TE (1998a) Accurate classification of juvenile weakfish Cynoscion regalis to estuarine nursery areas based on chemical signatures in otoliths. Mar Ecol Prog Ser 173:253-265

Thorrold SR, Jones CM, Campana SE, McLaren JW, Lam JWH (1998b) Trace element signatures in otoliths record natal river of juvenile American shad (Alosa sapidissima). Limnol Oceanogr 43:1826-1835

Thorrold SR, Latkoczy C, Swart PK, Jones CM (2001) Natal homing in a marine fish metapopulation. Science 291: 297-299

Thresher RE (1999) Elemental composition of otoliths as a stock delineator in fishes. Fish Res 43:165-204

Tsukamoto K, Arai T (2001) Facultative catadromy of the eel Anguilla japonica between freshwater and seawater habitats. Mar Ecol Prog Ser 220:265-276

Vasconcelos RP, Reis-Santos P, Fonseca V, Maia A and 5 others (2007) Assessing anthropogenic pressures on estuarine fish nurseries along the Portuguese coast: a multimetric index and conceptual approach. Sci Total Environ 374:199-215

Veiga P, Vieira L, Bexiga C, Sá R, Erzini K (2006) Structure and temporal variations of fish assemblages of the Castro Marim salt marsh, southern Portugal. Estuar Coast Shelf Sci 70:27-38

Submitted: January 31, 2007; Accepted: June 18, 2007

Proofs received from author(s): November 2, 2007 